\title{
Influence of Prion Protein Genotypes on Milk Production Traits in Spanish Churra Sheep
}

\author{
L. Álvarez, B. Gutiérrez-Gil, F. San Primitivo, L. F. de la Fuente, and J. J. Arranz ${ }^{1}$ \\ Departamento de Producción Animal, Facultad de Veterinaria, Universidad de León, 24071, León, Spain
}

\begin{abstract}
The aim of this work was to analyze the possible relationships between milk production traits and prion protein genotypes in Spanish Churra sheep. For this purpose, 2 analyses were carried out. First, an association study was performed of the prion protein genotypes of 12,533 Churra ewes and their milk yield, protein percentage, fat percentage, and somatic cell score as phenotypes, followed by a quantitative trait loci screening on the chromosome where the prion protein gene was located in this population. The latter analysis was carried out using 8 genetic markers ( 7 microsatellites and the prion protein genotypes) spanning ovine chromosome 13 using a daughter design. Regarding genotype frequencies, the most frequent allele was ARQ $(75.90 \%)$, which linked with a high susceptibility to scrapie, followed by the resistant haplotype, ARR (18.16 $\%)$. The frequency of the most susceptible allele, VRQ, was around 1\%. No evidence of association or linkage between prion protein genotypes and milk traits has been detected in Churra sheep. These results indicate that increasing the ARR frequency in Churra population will not have an adverse effect on selection for milk traits included in the breeding objectives. However, the low allele frequencies for ARR should be considered in the initial stages to prevent possible bottlenecks in future genetic progress.
\end{abstract}

Key words: Churra dairy sheep, prion protein gene, milk production, scrapie resistance

\section{INTRODUCTION}

Scrapie is a fatal neurodegenerative disease occurring in sheep and goats. The exact nature of the infectious agent is not known but it is widely believed to be an infectious protein called a prion (Prusiner, 1998). A prion is a cellular protein, encoded by an autosomal gene (PRNP), which would acquire pathogenic and infectious properties following its conversion from

Received June 30, 2005.

Accepted December 11, 2005.

${ }^{1}$ Corresponding author: jjarranz@unileon.es the normal isoform $\left(\mathrm{PrP}^{\mathrm{C}}\right)$ to the structurally modified isomer $\left(\mathrm{PrP}^{\mathrm{SC}}\right)$. All mammalian genomes that have been analyzed contain a copy of the PRNP gene. Ovine PRNP spans $31 \mathrm{~kb}$ and consists of 2 short, noncoding exons, plus a third exon containing the open reading frame spanning $771 \mathrm{bp}$ (256 codons; Lee et al., 1998). This gene has been mapped by physical procedures to ovine chromosome 13 (OAR13; Castiglioni et al., 1998).

There is strong evidence that different polymorphisms in the PrP coding gene cause variable incubation periods and, possibly, degrees of resistance to scrapie in sheep. Susceptibility to scrapie in sheep is closely linked to variations at codons 136, 154, and 171 . The most frequent amino acids coded for at these 3 codons are: alanine (A) or valine (V) at codon 136; arginine $(\mathrm{R})$ or histidine $(\mathrm{H})$ at codon 154; and glutamine $(\mathrm{Q})$, histidine $(\mathrm{H})$, or arginine $(\mathrm{R})$ at codon 171 . The 5 most common haplotypes (ARQ, ARR, AHQ, ARH, and VRQ) give 15 possible different PRNP genotypes, the most resistant of which in all sheep breeds is homozygous ARR/ARR, for adenine ${ }_{136}$, arginine $_{154}$, and arginine $_{171}$ (Hunter, 1997).

Based on this knowledge, the European Commission (2003) introduced regulations on the selection for further breeding of sheep that are genetically resistant to transmissible spongiform encephalopathies (e.g., scrapie and bovine spongiform encephalopathy) to eradicate these diseases through an animal genotyping scheme (European Commission Decision 2003/100/CE). The selection programs began in April 2005 and are designed to increase the frequency of the ARR allele and reduce the incidence of alleles with a high susceptibility to transmissible spongiform encephalopathies. One of the most important points is to review any serious negative genetic effect of the PRNP gene or any other gene located in its vicinity. Other possible constraints on selection programs for scrapie resistance will arise in populations with low or moderate frequencies of the ARR allele. In these cases the main problem will be a reduction in the number of animals available for selection as progenitors of the next generation if selection pressure is high during the first steps.

Churra sheep are a native Spanish breed used mainly for milk production. A selection scheme was established 
in 1989, and the most important traits recorded are milk yield and milk quality (fat content, protein percentage, and SCC). The decision of the European Commission could interfere with sheep selection programs, because it prioritizes the use of resistant animals for breeding regardless of their performance. Selection for the ARR/ARR genotype could induce a simultaneous change in production traits due to either the pleiotropy of the PRPN gene or genetic linkage with QTL. Therefore, it is important to rule out the possibility of an increased ARR frequency having an adverse effect on the selection for other traits such as production or functional traits included in breeding programs. The aim of this study was to estimate the possible relationship between PRNP genotypes and the dairy traits used in the Churra selection scheme. A 2-step analysis was carried out: we first performed an association analysis in the Churra population, followed by screening for quantitative trait loci that affect milk traits on chromosome 13, using a daughter design.

\section{MATERIALS AND METHODS}

\section{Association Study}

Animals and Measurements. In the first study, 12,553 ewes belonging to 27 flocks owned by Churra Association Breeders were genotyped to discern their protective status against scrapie. All the animals belonged to 568 half-sib families; 223 generated by AI with a total of 7,378 ewes; and the remaining 5,283 ewes were daughters of 345 rams used in natural service. The ewes had milk yield, protein percentage, fat percentage, and SCC recorded under the official testing program of the Churra selection scheme from 1995 through 2004. These measurements included 82,854 test-day records for milk yield, protein and fat percentages, and SCS. Each ewe averaged 3.1 test-day records and 2.13 lactations. Milk recording information was detailed in the work of El Saied et al. (1999).

Single Nucleotide Polymorphism Genotyping. DNA was obtained from whole blood using magnetic beads by means of a Chemagic DNA animal blood kit (Chemagen, Baesweiler, Germany). Genotypes of codons 136,154 , and 171 of the PRNP gene were obtained using the primer extension method with the SNaPshot multiplex kit (Applied Biosystems, Foster City, CA). The experimental procedures are described in detail by Álvarez et al. (2006). Briefly, 2 primers were designed to amplify a 356-bp DNA fragment of exon 3 of the PRNP gene comprising codons 136,154 , and 171 . The purified PCR fragment was used as a template in microsequencing by $\mathrm{SNaPshot} \mathrm{reaction} \mathrm{performed} \mathrm{with} 4$ oligonucleotides, as described by Álvarez et al. (2006).
After shrimp alkaline phosphatase treatment (USB Corporation, Cleveland $\mathrm{OH}$ ), the fluorescently labeled dideoxy-terminated fragments were analyzed on $\mathrm{AB}$ IPrism377 Genetic Sequencer and genotypes were identified using GeneScan and Genotyper programs (Applied Biosystems).

Statistical Analysis. The effects of a PRNP haplotype on milk traits (milk yield, fat content, protein content, and SCS) were estimated assuming the following univariate model:

$\mathrm{Y}_{\mathrm{ijklm}}=\mu+\mathrm{FTS}_{\mathrm{i}}+\mathrm{LG}_{\mathrm{j}}+\mathrm{WL}_{\mathrm{k}}+\mathrm{GE}_{\mathrm{l}}+\mathrm{a}_{\mathrm{m}}+\mathrm{p}_{\mathrm{m}}+\mathrm{e}_{\mathrm{ijklm}}$

where $Y_{\mathrm{ijklm}}=$ dependent variable indicated as test day records for milk yield, protein percentage fat percentage and SCS; $\mu=$ population mean; FTS $_{\mathrm{i}}=$ fixed effect of flock-test-date i (3,055 levels); $L_{\mathrm{j}}=$ fixed effect of lambing age $\mathrm{j}\left(5\right.$ levels); $\mathrm{WL}_{\mathrm{k}}=$ fixed effect of week of lactation $\mathrm{k}$ (16 levels; from wk 4 to wk 19 after lambing); $\mathrm{GE}_{1}=$ fixed effect of the genotype of PRNP $\mathrm{m}$ (6 levels); $\mathrm{a}_{\mathrm{m}}=$ random additive genetic effect of the animal $m(19,388$ levels; 12,553 for ewes with records); $\mathrm{p}_{\mathrm{m}}=$ random permanent environmental effect of the animal $\mathrm{m}(12,553$ levels); and $\mathrm{e}_{\mathrm{ijklm}}=$ random residual effect.

Genetic parameters were estimated by the analytical gradients (AG) REML procedure (Neumaier and Groeneveld, 1998) using the variance component estimation program, VCE4 package (Groeneveld, 1998). Contrasts between different PRNP genotypes classes were calculated for each milk production trait using PEST 3.1 software (Groeneveld, 1993) with the genetic parameters estimated previously for this data set.

To obtain a better distribution of frequencies between comparison groups, the 15 genotypes were divided into 6 groups, based on a scrapie-susceptibility criterion established by the European Commission (2004). The first group was of scrapie-resistant animals or homozygous ARR/ARR. The second comprised nonsusceptible ewes (ARR/XXX). The third and fourth groups comprised susceptible and neutral animals (AHQ/XXX and ARH/ XXX, respectively). The wild-type vulnerable animals (ARQ/ARQ) constituted the fifth group. Finally, the highly susceptible animals included all VRQ carriers.

\section{QTL Detection}

Experimental Design. A daughter design was carried out with families belonging to the Spanish Churra dairy sheep selection scheme. Eleven families comprising 1,420 ewes were investigated to map QTL influencing milk yield and composition. The average size of each family was around 130 ewes per ram, with a range from 77 to 256 . Ewes belonging to each family were 
daughters of the same ram and different dams generated by use of AI in Churra sheep; only 6 animals from different families were full sibs. Eight genetic markers spanning OAR13 were analyzed. Seven microsatellites were chosen from the ovine linkage map (Maddox, 2001) and the last marker was the PRNP polymorphism at codons 136, 154, and 171. This gene was not included in the ovine linkage map, but it was located by hybridization techniques on chromosome 13 (Castiglioni et al., 1998).

Primers for microsatellites (AGLA285, BMC1222, BMS1669, BMS995, HUJ616, OARAE16, and TGLA23) were chosen from the Australian sheep gene mapping Web site (http://rubens.its.unimelb.edu.au/ jillm/ jill.htm). Genotypes for the PRNP gene were carried out as above.

Map Construction. A male linkage map was calculated from the allele identification data, using the CRIMAP program (Lander and Green, 1987) to estimate distances from recombination rates.

QTL Analysis. Analysis of QTL was carried out on OAR13 for production traits using multiple marker regression data to detect QTL by applying a weighted cross-family analysis to each trait separately with the model described by Díez-Tascón et al. (2001). The phenotypes used for linkage analysis were yield deviations estimated as weighted averages of ewes' performances expressed as deviations from the population mean for milk yield, protein percentage, fat percentage, and SCS. The yield deviations were obtained directly from the Churra Association Breeders selection scheme. Chromosome-wise critical values were calculated through 10,000 phenotype permutations. Values of the information content were estimated following Coppieters et al. (1998).

\section{RESULTS AND DISCUSSION}

Table 1 shows the number of animals observed for each genetic variant, together with genotypic and allelic frequencies in Churra sheep. All 15 possible genotype combinations were detected for the 5 alleles described at codons 136, 154, and 171 in the ovine PRNP gene. The most frequent genotype in Churra sheep was ARQ/ ARQ at $57.67 \%$ (7,239 animals), followed by ARR/ARQ genotype (3,481 animals, or $27.73 \%)$. The frequency of the genotypes ARR/AHQ, ARR/ARH, AHQ/AHQ, AHQ/ ARH, ARH/ARH, ARQ/VRQ, ARR/VRQ, AHQ/VRQ, $\mathrm{ARH} / \mathrm{VRQ}$, and VRQ/VRQ was close to or less than $1 \%$. According to these data, only $3.20 \%$ of the Churras belong to the genotype most resistant to scrapie infection (ARR/ARR), whereas almost $30 \%$ enjoy a good protective status (heterozygous ARR noncarriers of VRQ). The most common genetic variant is the so-called wild-
Table 1. Numbers of animals observed for each genotype and their genotype and allele frequencies in percentages in Churra sheep

\begin{tabular}{lrc}
\hline Genotype & Number & Frequency $(\%)$ \\
\hline ARR/ARR & 402 & 3.20 \\
ARR/AHQ & 92 & 0.73 \\
ARR/ARH & 127 & 1.01 \\
ARR/ARQ & 3,481 & 27.73 \\
AHQ/AHQ & 8 & 0.06 \\
AHQ/ARH & 16 & 0.13 \\
ARQ/AHQ & 391 & 3.12 \\
ARH/ARH & 18 & 0.14 \\
ARQ/ARH & 532 & 4.24 \\
ARQ/ARQ & 7,239 & 57.67 \\
ARR/VRQ & 54 & 0.43 \\
AHQ/VRQ & 9 & 0.07 \\
ARH//VRQ & 6 & 0.05 \\
ARQ/VRQ & 173 & 1.38 \\
VRQ/VRQ & 5 & 0.04 \\
Total & 12,553 & 100 \\
Allele & & \\
ARR & & 18.16 \\
AHQ & & 2.09 \\
ARH & & 2.85 \\
ARQ & & 1.00 \\
VRQ & & \\
\hline
\end{tabular}

type allele in sheep (ARQ), with a frequency of $75.9 \%$ and linked with high susceptibility to scrapie, followed by the haplotype ARR, at $18.16 \%$. The frequency of the most susceptible haplotype, VRQ, is small but present at $1 \%$. In the light of these frequencies, Churras could be considered one of the so-called alanine breeds, owing to the high prevalence of wild-type ARQ and the residual frequency of VRQ (Baylis and Goldmann, 2004). The proportions of AHQ and ARH were low: 2.09 and $2.85 \%$, respectively. The susceptibility of these variants is still unknown in Churra sheep; nevertheless, in other populations, ARQ and AHQ show erratic behavior. In some breeds, AHQ is associated with increased resistance and long incubation periods (Hunter, 1997; Elsen et al., 1999), whereas in other populations it is related to high susceptibility to scrapie (Moum et al., 2005). Allele ARH seems to be neutral in most cases (Baylis and Goldmann, 2004). Recently, new haplotypes (VRR, $\mathrm{AHR}$, and $\mathrm{AHQ}$ ) have been identified at low frequency in some breeds and their association with scrapie is unknown (Goldmann et al., 2005). According to Álvarez et al. (2006), there is no evidence of these new alleles in Churra sheep, although another new allele, ALQ, has been found in one ewe and her lamb. These 2 animals were excluded from association or QTL analyses.

The frequencies observed in Churra sheep are similar to those of other native Iberian breeds analyzed, in which the ARQ allele may be found in more than $60 \%$, allele ARR has low frequencies, and VRQ are close to or less than 1\% (Acin et al., 2004; Orge et al., 2004; Álvarez et al., 2006). 
Table 2. Means, standard deviations, additive genetic variances $\left(\sigma_{\mathrm{a}}^{2}\right)$, and heritabilities $\left(\mathrm{h}^{2}\right)$, and permanent environmental variance proportions $\left(\mathrm{C}^{2}\right)$ for milk yield, fat and protein percentage, and $\mathrm{SCS}^{1}$

\begin{tabular}{llllll}
\hline Trait & Mean & $\mathrm{SD}$ & $\sigma_{\mathrm{a}}{ }^{2}$ & $\mathrm{~h}^{2}( \pm \mathrm{SE})$ & $\mathrm{C}^{2}( \pm \mathrm{SE})$ \\
\hline Milk yield, kg/d & 1.112 & 0.529 & 0.022 & $0.13 \pm 0.01$ & $0.19 \pm 0.01$ \\
Protein content, \% & 5.561 & 0.794 & 0.082 & $0.25 \pm 0.02$ & $0.10 \pm 0.01$ \\
Fat content, \% & 6.684 & 1.683 & 0.170 & $0.09 \pm 0.01$ & $0.07 \pm 0.01$ \\
SCS & 5.397 & 0.716 & 0.028 & $0.06 \pm 0.01$ & $0.22 \pm 0.01$ \\
\hline
\end{tabular}

${ }^{1} \mathrm{SCS}=$ Test-day SCC converted to a $\log$ scale.

\section{Association Study}

Table 2 contains the means and their standard deviations, additive genetic variances, heritabilities, permanent environmental variances, and their standard errors for the test-day variables analyzed. These values were estimated from the 12,322 ewes with milk records included in the association analysis. Our estimates fall within the range frequently obtained for Churra sheep in previous studies (El-Saied et al., 1999; Othmane et al., 2002) and other dairy sheep (Hamann et al., 2004) except for fat content. For fat percentage, our results were probably influenced by the enormous variability in milking practices and management for the Churra breed (e.g., hand stripping, nutrition), and possibly the effects of poor sample collection.

In addition, milk fat content variability seems especially influenced by feeding (Othmane et al., 2002). The low heritability of SCS (0.06) was lower than other estimates in Churra sheep (El-Saied et al., 1999; Othmane et al., 2002). This lower value of heritability for SCS could be due to analysis of a large number of flocks with different parity systems and milking routines that could increase the heterogeneity of our data set compared with those in previous studies.

The effect of the PRNP genotype is shown in Table 3 , in which the estimated differences (least squares mean) for the analyzed traits between the wild-type genotype (ARQ/ARQ) and the diverse genotype classes defined in the Material and Methods section are presented. No significant differences were detected between the diverse risk-groups analyzed for milk yield. The general figures indicate that there is a small difference among ARQ/ARQ, AHQ/XXX, and ARH/XXX, whereas there are slightly negative differences between the wild type and the most resistant genotypes (albeit never significant). Concerning milk quality traits, no significant association with protein and fat percentage has been detected. In the case of SCS, animals belonging to the ARR/XXX genotype class showed a lower level of somatic cells compared with the wild type genotype, but no significant differences were found in any case. Our results are in accordance with an association study performed on other Spanish breeds (Legarra et al., 2004) and on German East Friesian milk sheep by De Vries et al. (2005), in which no evidence was found of any link between PRNP genotypes and milk yield fat content, protein content, and SCS. These results show an imbalanced distribution of animals in the diverse genotype groups analyzed and genotypes other than $\mathrm{ARQ} / \mathrm{ARQ}$ and ARR/XXX show very small frequencies (between $1.97 \%$ for VRQ carriers and $4.38 \%$ for ARH/ XXX).

\section{QTL Analysis}

Figure 1 depicts the marker map obtained by multipoint analysis, as well as the information content along $137 \mathrm{cM}$ (Haldane) obtained from the Churra sheep daughter design. Marker position and map distances are in agreement with published ovine linkage maps (http://rubens.its.unimelb.edu.au/ jillm/jill.htm; http://www.marc.usda.gov/). This marker map shows that nearly $60 \%$ of the available information originates from pedigree material. The most effective interval is HUJ616-PRNP, where more than 70\% of daughters are informative. The great distance between BMS1669 and BMS995 (37 cM or $32 \%$ of recombinants) gave the lowest value for the information content in the middle of this interval, $34.5 \%$. The PRNP locus is informative in 4 of the 11 half-sib families and is located in the linkage map at $73.9 \mathrm{cM}$ (Haldane) between microsatellites HUJ616 and BMS1669, which have recombination fractions of 0.06 and 0.07 , respectively. The position of the PRNP locus in chromosome 13, presented here, is in agreement with fluorescent in situ hybridization results presented by Castiglioni et al. (1998).

Figure 2 shows the probability profile along $137 \mathrm{cM}$ of the map from multimarker regression analysis across families. The curves measure the $\log _{10}$ of the inverse of the chromosome-wise $P$-values of the data under the null hypothesis of no QTL at the corresponding position estimated from 10,000 permutations. There is no evidence in favor of a QTL along the chromosome 13 map for the 4 traits studied. However, in the central region of the chromosome, at 69 to $100 \mathrm{cM}$, a slight decrease in the $P$-values of milk yield could be observed. In this 
Table 3. Least squares means ( $\pm \mathrm{SE}$ ) and estimated differences (Dif.) from homozygous ARQ/ARQ genotype of milk yield, fat and protein percentage, and SCS in association analysis ${ }^{1}$

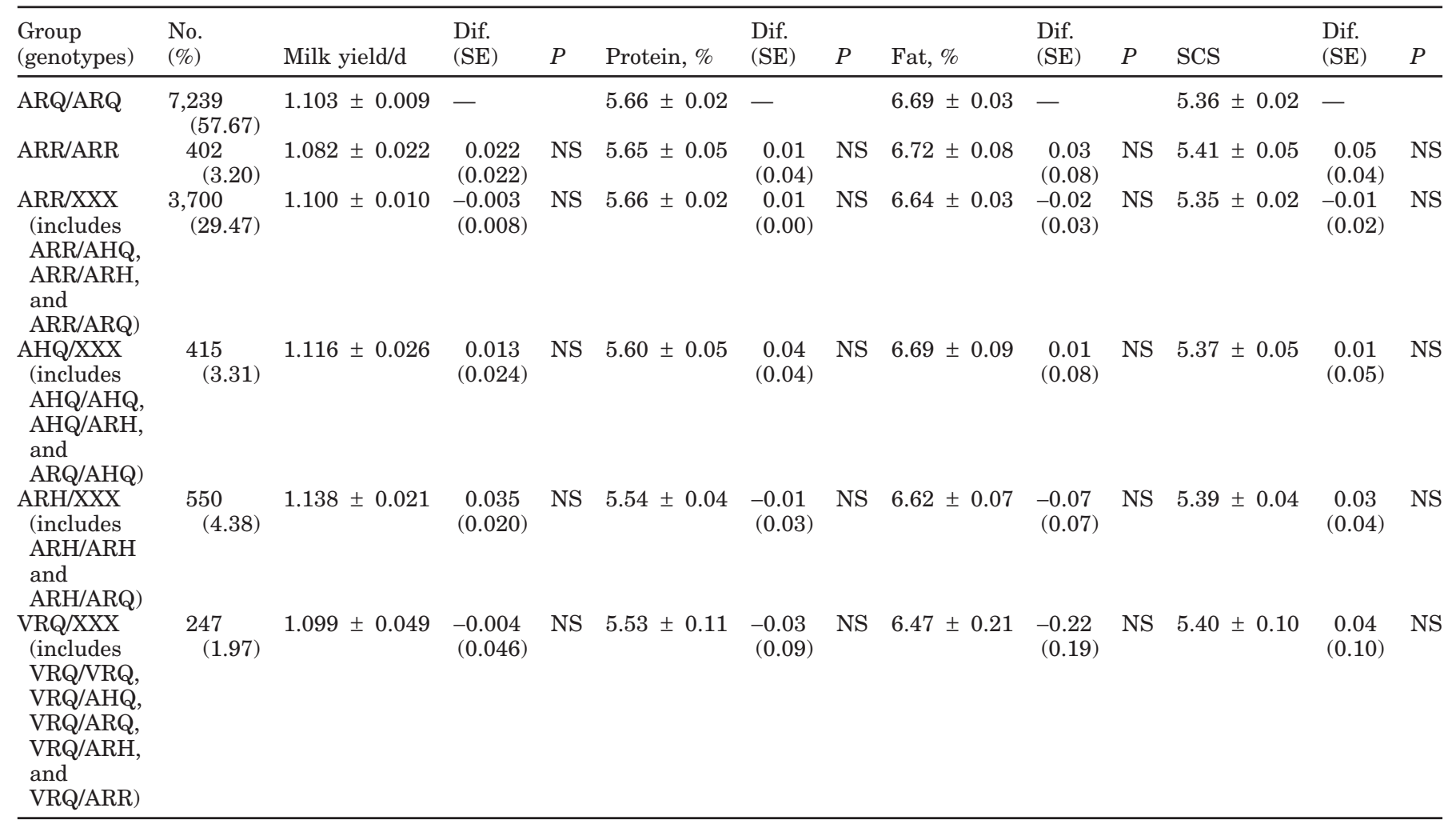

${ }^{1}$ Animals are grouped by genotype according to scrapie risk.

region, chromosome-wise $P$-values reached 0.17 and 0.24 , too high for a QTL to affect milk yield in chromosome 13.
Regarding SCS, there is no clear evidence of a QTL affecting this trait along OAR13, but at the telomeric region of the chromosome, the $P$-value reaches a magni-

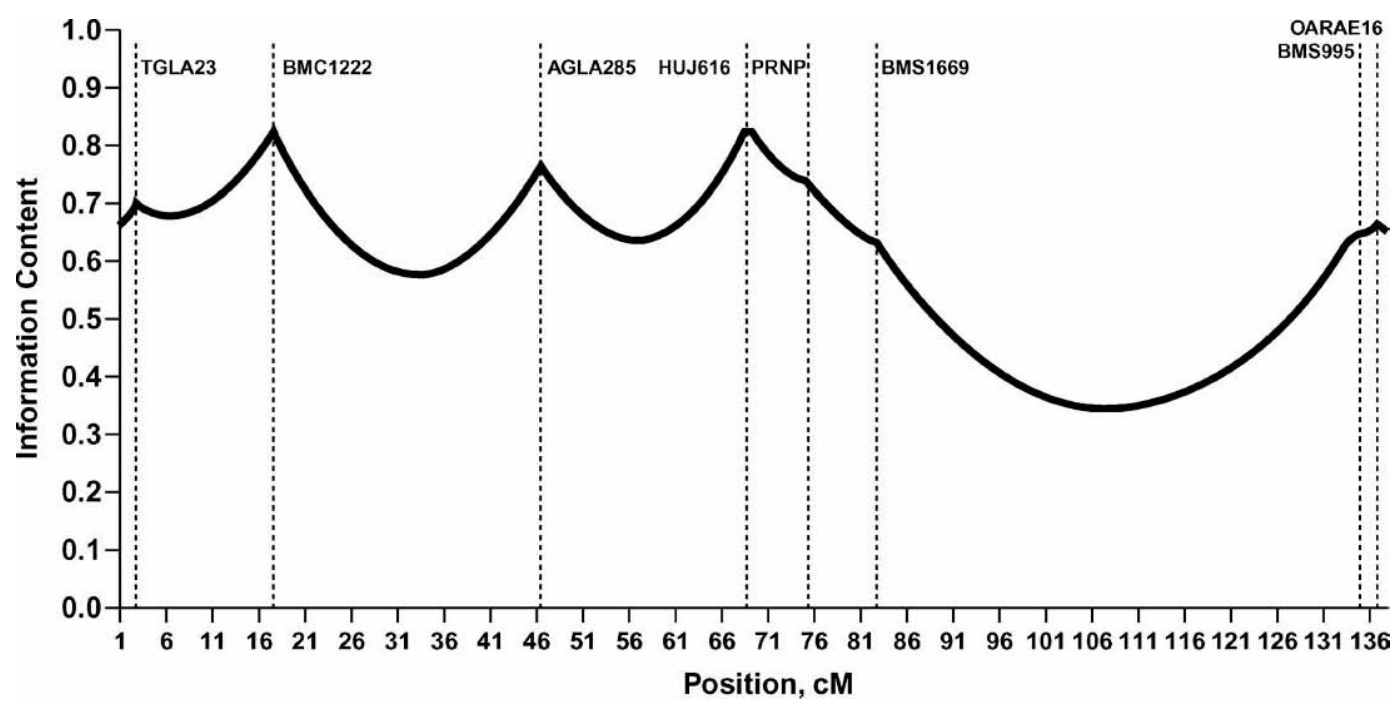

Figure 1. Information content of the chromosome 13 map used. Marker position is indicated by vertical lines with marker names at the top and marker position in $\mathrm{cM}$ at the bottom. 


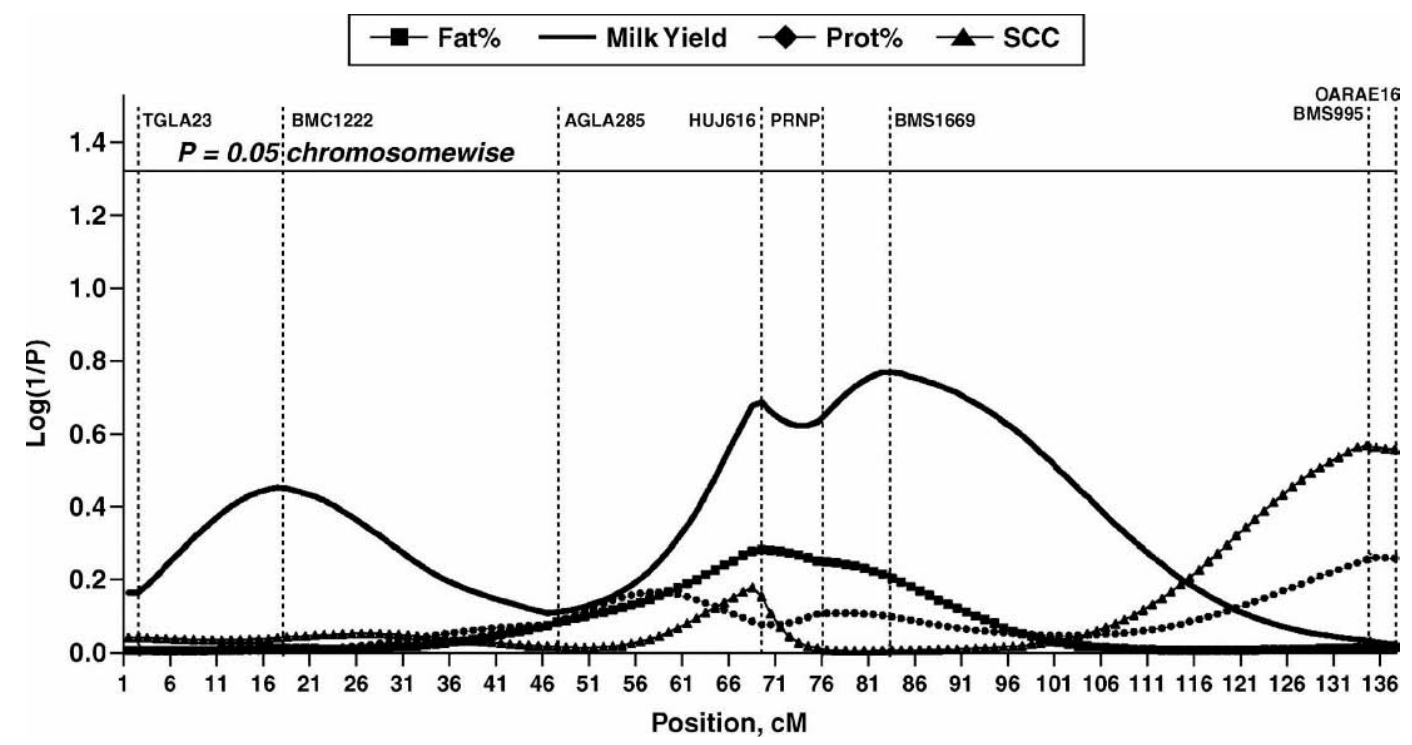

Figure 2. Location scores obtained for the daughter design. The y axis represents evidence in favor of a QTL measured as $\log _{10}(1 / \mathrm{P})$, where $\mathrm{P}$ is the associated chromosome-wise $P$-value determined by 10,000 phenotype permutations.

tude of 0.17 , which is not significant at the chromosome level. The results presented here do not support a real QTL affecting SCS segregating in the Churra population.

The power of our design was estimated following Weller et al. (1990) as the probability of significantly detecting a true QTL in similar conditions to our QTL search experiment. The value obtained was $56 \%$ considering a biallelic QTL of 0.3 phenotypic standard deviations with an allele frequency of 0.5 in a population with similar properties to our daughter design and heritability to 0.25 , for a type error I set to 0.05 , and $10 \%$ of recombination fraction between QTL and marker.

The QTL analysis results revealed no direct effect of the PRNP locus or closely linked genes on analyzed milk traits in Churra sheep. These findings were in concordance with the results of Barillet et al. (2002) for Lacaune sheep using a granddaughter design and PRNP as a single genetic marker. These authors did not find any evidence supporting a QTL near the PRNP gene. In our case, the use of 8 genetic markers spanning most of OAR13 gives a more global picture of the possibility of linkage between PRNP and a putative QTL on chromosome 13.

One point to consider here is the consistency of our results. Regarding QTL searching, our design has a medium theoretical power to detect a segregating QTL (56\%) in our population; nevertheless, this type of design has been very effective in the detection of genes with effects on productive characters in ruminants (Barillet et al., 2005). Another aspect to consider is that the lack of significance in these genomic regions cannot completely exclude the existence of genes that affect milk production. A linkage exclusion analysis could be more suitable for this purpose as has been demonstrated in human populations by Yang et al. (2005). As far as we know, this type of analysis has not been made in complex pedigrees such as the large half-sib families used in this study. Nevertheless, the coincidence in lack of association when using 2 complementary analyses makes our results more convincing in this regard.

For these reasons, our results indicate that increasing the ARR frequency in Churra population will not have an adverse effect on selection for milk traits included in the breeding objectives either by a direct effect of the PRNP gene on these traits or by a linkage between this locus and a putative QTL. However, the population allele frequencies for ARR should be considered during establishment of the selection scheme for increasing scrapie resistance. In the case of the Churra breed, the starting point is less favorable for a meaningful selection for ARR because only around $3.5 \%$ of animals are ARR/ARR and a bottleneck will occur if only homozygous resistant animals are allowed in the first stages of a selection program for scrapie resistance. This process will affect both the consanguinity and the genetic progress of the population, and will have a negative effect on the milk yield of Churra sheep. Therefore, in sheep populations such as Churra, selection processes should contemplate population size and frequencies, especially in areas where scrapie incidence is uncommon.

Another important point is the appearance of new scrapie strains affecting resistant animals. A new 
strain of scrapie, Nor98, was detected in Norway in 1998. It mainly affects animals carrying the AHQ haplotype, which is supposed to be resistant to scrapie, and has now been detected in several European countries including Sweden, Finland, Ireland, and Belgium (Baylis and McIntyre, 2004). Atypical forms of scrapie have been reported in supposedly resistant sheep in Germany, Portugal, and France (Buschmann et al., 2004; Orge et al., 2004). These cases showed some similarity to the new Nor98 strain. These new variants of scrapie showed that sheep largely resistant to known strains might be highly susceptible to new strains as yet unidentified, and the more susceptible VRQ may be resistant to these new scrapie strains (Baylis and McIntyre, 2004). The appearance of new strains and the possibility of coevolution between host and pathogen (Woolhouse et al., 2002) could influence scrapie eradication strategies based on selective breeding.

\section{CONCLUSIONS}

The results presented here lend weight to the hypothesis that increasing resistance to scrapie in the Spanish Churra population will have no adverse effect on selection for milk traits. However, allelic frequency of the ARR resistant allele and the low incidence of scrapie make it advisable to start a slow selection program to avoid the negative effects (bottleneck, drop of genetic progress) of intensive selection.

\section{ACKNOWLEDGMENTS}

We thank Yolanda Bayon and Usama El Saied for fruitful discussions. This work was supported by the Spanish Ministry of Education and Culture (Project EET2003-00079) and European Union though the project genesheepsafety (QLK5-2000-00656).

\section{REFERENCES}

Acin, C., I. Martin-Burriel, W. Goldmann, J. Lyahyai, M. Monzon, R. Bolea, A. Smith, C. Rodellar, J. J. Badiola, and P. Zaragoza. 2004. Prion protein gene polymorphisms in healthy and scrapieaffected Spanish sheep. J. Gen. Virol. 85:2103-2110.

Álvarez, L., J. J. Arranz, and F. San Primitivo. 2006. Identification of a new leucine haplotype (ALQ) at codon 154 in the ovine prion protein gene in Spanish sheep. J. Anim. Sci. 84:259-265.

Barillet, F., O. Andreoletti, I. Palhière, X. Aguerre, J. M. Arranz, S. Minery, C. Soulas, J. P. Belloc, M. Briois, G. Frégeat, P. Teinturier, Y. Amigues, J. M. Astruc, M. Y. Boscher, and F. Schelcher. 2002. Breeding for scrapie resistance using PrP genotyping in the French dairy sheep breeds. 7th World Congr. Genet. Appl. Livest. Prod. Montpellier, France. 31:683-686.

Barillet, F., J. J. Arranz, and A. Carta. 2005. Mapping quantitative trait loci for milk production and genetic polymorphisms of milk proteins in dairy sheep. Genet. Sel. Evol. 37(Suppl. 1):S109-S123.

Baylis, M., and W. Goldmann. 2004. The genetics of scrapie in sheep and goats. Curr. Mol. Med. 4:385-396.
Baylis, M., and K. M. McIntyre. 2004. Transmissible spongiform encephalopathies. Scrapie control under new strain. Nature 432:810-811.

Buschmann, A., A. G. Biacabe, U. Ziegler, A. Bencsik, J. Y. Madec, G. Erhardt, G. Lühken, T. Baron, and M. H. Groschup. 2004. Atypical scrapie cases in Germany and France are identified by discrepant reaction patterns in BSE rapid tests. J. Virol. Method 117:27-36.

Castiglioni, B., S. Comincini, B. Drisaldi, T. Motta, and L. Ferretti. 1998. Comparative mapping of the prion gene (PRNP) locus in cattle, sheep and human with PCR-generated probes. Mamm. Genome 9:853-855.

Coppieters, W., A. Kvasz, F. Farnir, J. J. Arranz, B. Grisart, M. Mackinnon, and M. Georges. 1998. A rank-based nonparametric method for mapping quantitative trait loci in outbred half-sib pedigrees: Application to milk production in a granddaughter design. Genetics 149:1547-1555.

De Vries, F., H. Hamann, C. Drögemüller, M. Ganter, and O. Distl. 2005. Analysis of associations between the prion protein genotypes and production traits in East Friesian milk sheep. J. Dairy Sci. 88:392-398.

Díez-Tascón, C., Y. Bayon, J. J. Arranz, L. F. de la Fuente, and F. San Primitivo. 2001. Mapping quantitative trait loci for milk production traits on ovine chromosome 6. J. Dairy Res. 68:389-397.

El-Saied, U. M., J. A. Carriedo, L. F. de la Fuente, and F. San Primitivo. 1999. Genetic parameters of lactation cell counts and milk and protein yields in dairy ewes. J. Dairy Sci. 82:639-644.

Elsen, J. M., Y. Amigues, F. Schelcher, V. Ducrocq, O. Androeletti, F. Eychenne, J. V. Khang, J. P. Poivey, F. Lantier, and J. L. Laplanche. 1999. Genetic susceptibility and transmission factors in scrapie: Detailed analysis of an epidemic in a closed flock of Romanov. Arch. Virol. 144:431-445.

European Commission. 2003. 2003/100/EC Commission decision laying down minimum requirements for the establishment of breeding programs for resistance to transmissible spongiform encephalopathies in sheep. Off. J. L 041:41-45.

European Commission. 2004. Report on the monitoring and testing of ruminants for the presence of transmissible spongiform encephalopathy (TSE) in the EU in 2003, including the results of the survey of prion protein genotypes in sheep breeds. European Union, Brussels, Belgium. Available: http://europa.eu.int/comm/ food/food/biosafety/bse/annual_report_tse2003_en.pdf

Goldmann, W., M. Baylis, C. Chihota, E. Stevenson, and N. Hunter. 2005. Frequencies of PrP gene haplotypes in British sheep flocks and the implications for breeding programmes. J. Appl. Microbiol. 98:1294-1302.

Groeneveld, E. 1993. PEST User's Manual. Institute of Animal Husbandry and Animal Behavior, Federal Agricultural Research Centre, Neustadt, Germany.

Groeneveld, E. 1998. VCE4 User's Guide and Reference Manual Version 1.1. Institute for Animal Science and Animal Husbandry, Federal Agricultural Research Centre, Neustadt, Germany.

Hamann, H., A. Horstick, A. Wessels, and O. Distl. 2004. Estimation of genetic parameters for test day milk production, somatic cell score and litter size at birth in East Friesian ewes. Livest. Prod. Sci. 87:153-160.

Hunter, N. 1997. Molecular biology and genetics of scrapie in sheep. Pages 225-240 in The Genetics of Sheep. L. Piper and A. Ruvinsky ed. CAB International, Wallingford, United Kingdom.

Lander, E. S., and P. Green. 1987. Construction of multilocus genetic linkage maps in humans. Proc. Natl. Acad. Sci. USA 84:23632367.

Lee, I. Y., D. Westaway, A. F. A. Smit, K. Wang, J. Seto, L. Chen, C. Acharya, M. Ankener, D. Baskin, C. Cooper, H. Yao, S. B. Prusiner, and L. E. Hood. 1998. Complete genomic sequence and analysis of the prion protein gene region from three mammalian species. Genome Res. 8:1022-1037.

Legarra, A., E. Ugarte, and I. Beltran de Heredia. 2004. Análisis de asociación y producción de leche en raza Latxa. ITEA 100A:127133. [In Spanish] 
Maddox, J. F. 2001. An enhanced linkage map of the sheep genome comprising more than 1000 loci. Genome Res. 1:1275-1289. Last update available at http://rubens.its.unimelb.edu.au/ jillm/ jill.htm

Moum, T., I. Olsaker, P. Hopp, T. Moldal, M. Valheim, T. Moum, and S. L. Benestad. 2005. Polymorphisms at codons 141 and 154 in the ovine prion protein gene are associated with scrapie Nor98 cases. J. Gen. Virol. 86:231-235.

Neumaier, A., and E. Groeneveld. 1998. Restricted maximum likelihood estimation of covariances in sparse linear models. Genet. Sel. Evol. 30:3-26.

Othmane, M. H., L. F. de la Fuente, J. A. Carriedo, and F. San Primitivo. 2002. Heritability and genetic correlations of test day milk yield and composition, individual laboratory cheese yield, and somatic cell count for dairy ewes. J. Dairy Sci. 85:2692-2698.
Orge, L., A. Galo, C. Machado, C. Lima, C. Ochoa, J. Silva, M. Ramos, and J. P. Simas. 2004. Identification of putative atypical scrapie in sheep in Portugal. J. Gen. Virol. 85:3487-3491.

Prusiner, S. B. 1998. Prions. Proc. Natl. Acad. Sci. USA 95:1336313383.

Weller, J. I., Y. Khasi, and M. Soller. 1990. Power of daughter and granddaughter designs for determining linkage between loci and quantitative trait loci in dairy cattle. J. Dairy Sci. 73:2525-2537.

Woolhouse, M. E., J. P. Webster, E. Domingo, B. Charlesworth, and B. R. Levin. 2002. Biological and biomedical implications of the coevolution of pathogens and their hosts. Nat. Genet. 32:569-577.

Yang, Y. J., Y. Z. Liu, M. X. Li, S. F. Lei, X. D. Chen, X. Sun, and H. W. Deng. 2005. Linkage exclusion analysis of two important chromosomal regions for height. Biochem. Biophys. Res. Commun. 335:1287-1292. 